\title{
İnflamatuar Barsak Hastalığında Adalimumab Tedavisinin Demir Parametreleri ve Anemi Üzerindeki Etkileri
}

\section{Effects of Adalimumab Treatment on Iron Parameters and Anemia in Inflammatory Bowel Disease}

\author{
Nimet YILMAZ ${ }^{1}$ \\ ${ }^{1}$ SANKO Üniversitesi, Tıp Fakültesi, Gastroenteroloji Bilim Dalı, Gaziantep, TÜRKiYE
}

öz.

Amaç: Bu çalışmada, Adalimumab tedavisinin inflamatuar barsak hastalı̆ında (iBH) demir parametreleri ve aneminin seyri üzerindeki etkisini değerlendirmek amaçlanmıştır.

Materyal ve Metod: 2016-2019 tarihleri arasında Sanko Üniversitesi Tıp Fakültesi Gastroenteroloji polikliniğinde takipli ve İH nedeniyle Adalimumab tedavisi uygulanan 33 hasta (19 Crohn ve 14 ülseratif kolit) çalışmaya dahil edilmiştir. Hastaların; yaş, cinsiyet, laboratuvar verileri (kan hemoglobin ( $\mathrm{Hb}$ ), hematokrit (Htc), lökosit (WBC), trombosit (Plt), demir (Fe), demir bağlama kapasitesi (DBK), transferrin saturasyonu, ferritin, C-reaktif protein (CRP) ve sedimantasyon düzeyleri) kaydedilmiștir. Tedavi öncesi ve 6 . aydaki değerler karşılaştırılmışırı. Klinik aktivite ülseratif kolit için ortalama parsiyel Mayo skoru (pMayo) ve Crohn hastalarında ortalama Harvey-Bradshaw Index (HBI) puanları karşılaştıılarak tedavi etkinliği değerlendirilmiştir. Değişkenlerin analizinde SPSS 26.0 programı kullanılmıştır. Değişkenler \%95 güven düzeyinde incelenmiş olup $p$ değeri 0,05 ten küçük anlamlı kabul edildi.

Bulgular: Sedimantasyon, CRP ve PIt değerlerinde tedavi sonrasında düşüş; $\mathrm{Hb}$, Htc ve demir değerlerinde anlamlı yükselme saptanmıştır. Transferrin satürasyonunda ise yükselme gözlenmiştir. Ancak bu istatistiksel olarak anlamlı fark oluşturmamıştır. Hb ve Htc değerlerindeki artışın ülseratif kolit grubunda daha fazla olduğu saptanmıştır. Klinik pMayo ve HBI skorlarında ise anlamlı düşüş olduğu saptanmıştır.

Sonuç: IBH nedeniyle Adalimumab tedavisi uygulanan hastalarda anemi düzelmektedir ve bu düzelme ülseratif kolit hastalarında daha belirgindir.

Anahtar kelimeler: İnflamatuar Barsak hastalığı, Ülseratif kolit, Adalimumab, Demir, Anemi

Abstract

Background: In this study, we aimed to evaluate the effect of Adalimumab treatment on iron parameters and the course of anemia in inflammatory bowel disease (IBD).

Materials and Methods: Thirty-three patients (19 Crohn's and 14 ulcerative colitis) who received Adalimumab treatment for IBD who were followed up in the Gastroenterology outpatient clinic of Sanko University Faculty of Medicine between 2016-2019 were included in the study. Age, gender, laboratory data (blood hemoglobin $(\mathrm{Hb})$, hematocrit $(\mathrm{Htc})$, leukocyte $(\mathrm{WBC})$, platelet $(\mathrm{Plt})$, iron $(\mathrm{Fe})$, iron binding capacity (DBK), transferrin saturation, ferritin, $C$ - reaktif protein ( CRP) and sedimentation levels) of the patients were recorded. Pre-treatment and 6th month values were compared. Clinical activity the efficacy of treatment was evaluated by comparing the mean partial Mayo score (pMayo) for ulcerative colitis and the mean Harvey-Bradshaw Index (HBI) scores in Crohn's patients. SPSS 26.0 program was used in the analysis of variables. Variables were analyzed at a $95 \%$ confidence level and a p value of less than 0.05 was considered to be significant.

Results: Decrease in sedimentation, CRP and PIt values after treatment; and significant increase was found in $\mathrm{Hb}, \mathrm{Htc}$ and iron values, respectively. An increase in transferrin saturation was observed. However, this did not create a statistically significant difference. It was determined that the increase in $\mathrm{Hb}$ and $\mathrm{Htc}$ values was more in the ulcerative colitis group. A significant decrease was found in clinical pMayo and HBI scores. Conclusions: Anemia improves in patients treated with Adalimumab for IBD, and this improvement is more pronounced in patients with ulcerative colitis.

Key Words: Inflammatory Bowel disease, Ulcerative colitis, Adalimumab, Iron, Anemia
Corresponding Author/Sorumlu Yazar

Dr. Nimet YILMAZ

SANKO Üniversitesi Tıp Fakültesi

Gastroenteroloji Bilim Dalı,

Gaziantep,Türkiye

E-mail: drnimet23@hotmail.com

Received / Geliş Tarihi: 22.02.2021

Accepted / Kabul Tarihi: 23.03.2021

DOI: $10.35440 /$ hutfd. 884032 


\section{Giriş}

Ülseratif Kolit (ÜK) ve Crohn hastalığı; gastrointestinal kanalın kronik, tekrarlayıcı, etyolojisi günümüzde henüz netleşmemiş olan inflamatuar barsak hastalıklarıdır (IBH) (1). Bu hastalıkların tedavisinde ise gelişen immün sürecin değişik basamaklarını engellemek hedeflenmiştir. Tümör nekrozis faktör alfa (TNF- $\alpha$ )'nın biyolojik aktivitelerini antagonize eden Adalimumab, İnfliksimab, ve Sertolizumab pegol'ün İBH immünopatogenezinde merkezi bir role sahip olduğu bilinmektedir $(2,3)$. Adalimumab insan TNF- $\alpha$ 'sına yüksek afinite ile bağlanarak biyolojik işlevlerini modüle eden rekombinant, tamamen insan kaynaklı bir IgG1 monoklonal antikorudur (4).

TNF- $\alpha$, inflamatuar aneminin indüklenmesinde rol oynamaktadır. Anti-TNF- $\alpha$ ajanlarının ise iBH'da anemi üzerindeki potansiyel etkisi henüz netleşmiş değildir $(5,6)$. Bununla birlikte aneminin ciddiyetinin IBH aktivitesi ile ilişkili olduğu ve IBH ile ilişkili mukozal inflamasyonu hafifletmek için kullanılan anti-TNF ilaçların anemiyi iyileştirebildiği çalışmalarda gösterilmiştir $(5,6)$.

Bu çalışmada, Adalimumab tedavisinin IBH' da demir parametreleri ve aneminin seyri üzerindeki etkisini değerlendirebilmek amaçlanmıştır.

\section{Materyal ve Metod}

2016-2019 tarihleri arasında Sanko Üniversitesi Tıp Fakültesi Gastroenteroloji polikliniğinde takipli, hastalık tanıları European Crohn's and Colitis Organisation (ECCO) kılavuzuna göre klinik, endoskopik ve histopatolojik olarak konulmuş ve anti-TNF tedavisi alan hastalar çalışmaya alınmıştır. Çalışmaya dahil edilen hastaların bilgilerine elektronik veri tabanından ulaşılmıştır. Hastaların; yaş, cinsiyet, laboratuvar verileri (kan hemoglobin $(\mathrm{Hb})$, hematokrit $(\mathrm{Htc})$, lökosit (WBC), trombosit (PLT), demir (Fe), demir bağlama kapasitesi (DBK), transferrin saturasyonu, ferritin, C-reaktif protein (CRP) ve sedimantasyon düzeyleri), cerrahi öyküsü, kronik hastalık varlığı, anemiye yönelik bir tedavi alıp almadığı ve kullandığı ilaçlar kaydedilmiştir. On sekiz yaş altı, daha önce herhangi bir anti-TNF ajan kullanmış olan, 3 ayIık rutin kontrollerine düzensiz gelen, tedavi başlangıcında ve takip eden haftalarda kan transfüzyonu, demir veya vitamin takviyesi almış olanlar, anemiye neden olabilecek kronik hastalığı olan ve bu nedenle ilaç kullananlar (böbrek yetmezliği, malignite, bağ dokusu hastalıkları veya hematolojik durumların varlığı) çalışmaya dahil edilmemiştir. Kliniğimizde toplam 46 hastaya Adalimumab tedavisi başlanmıştı ve dahil edilme kriterlerimize uyan 37 hasta mevcuttu. Fistülizan veya perianal tutulumlu olup ara kontrollerde çoklu antibiyotik tedavisi almış olan 4 Crohn hastası çalışmadan çıkarıldı ve ( $n=33$ (19 Crohn ve 14 ÜK)) çalışmaya dahil edildi. Tedavi başlangıcında hiçbir hastada aktif enfeksiyon olmadığı gösterilmişti.
İmmunomodülatör ve steroid tedavisine refrakter ortaağır aktiviteli hastalık nedeniyle anti- TNF tedavi başlanmış olan ÜK ve Crohn hastalarının her ziyaretinde tanımlanmış ve hasta dosyalarına işlenmiş olan klinik hastalık aktivitesi puanları da kaydedildi. Yaklaşık üç ayda bir poliklinik kontrolüne gelen hastalarda ÜK için klinik hastalık aktivitesi parsiyel Mayo skoru (pMayo) (hafif aktivite: 2-4; orta aktivite: 5-7; şiddetli aktivite:>7) kullanılarak değerlendirilmişti. Crohn hastalığı için ise klinik hastalık aktivitesi Harvey-Bradshaw indeksi (HBI) (hafif aktivite: 5-7; orta aktivite: 8-16; şiddetli aktivite:> 16) ile değerlendirilmişti (7). ÜK için pMayo skorunda ve Crohn hastalığı için HBI'da en az iki puanlık bir azalma, tedaviye klinik yanıtın göstergesi olarak kabul edildi.

Anti-TNF tedavisinin 8-16. haftasında semptomatik düzelme ve biyogöstergelerde iyileşme varsa remisyon kabul edilmektedir. Bu nedenle çalışmamızda tedavinin 6. ayındaki veriler değerlendirilmiştir. Tüm hastalara, Adalimumab enjeksiyonları T 0, 2. hafta, 4. hafta (160-80-40mg / subkutan enjeksiyon) aynı dozda uygulanmıştır. İdame tedavide ise bütün hastalar iki haftada bir 40 mg Adalimumab tedavisini subkutan almıştı.

Tedavi öncesi ve tedavinin altıncı ayındaki değerler karşılaştırılarak Adalimumab tedavisinin ' $\mathrm{BH}^{\prime}$ da demir parametreleri ve aneminin seyri üzerindeki etkisi incelendi. Ayrıca tedavi öncesi ve sonrasında ÜK hastalarında ortalama pMayo ve Crohn hastalarında ortalama HBI puanları karşılaştırılarak tedavi etkinliği değerlendirildi (8).

Çalışma Sanko Üniversitesi Tıp Fakültesi Etik Kurulunun 21.01.2021 tarih ve 2021/01 nolu etik izni ile yapılmıştır. Değişkenlerin analizinde SPSS 26.0 (IBM Corporation, Armonk, New York, United States) ve PAST 3 (Hammer, $\varnothing$., Harper, D.A.T., Ryan, P.D. 2001. Paleontological statistics) programları kullanıldı. Tek değişkenli verilerin normal dağılıma uygunluğu Shapiro-Wilk francia testi ile değerlendirilirken varyans homojenliği Levene testi ile değerlendirildi. Çok değişkenli verilerin normal dağılıma uygunluğu için Mardia; (Dornik and Hansen omnibüs) testi kullanılırken varyans homojenliği için Box-M testi kullanıldı. Bağımsız iki grubun nicel verilere göre birbiri ile karşılaştırılmasında Independent-Samples T testi kullanılırken Mann-Whitney U testi Monte Carlo sonuçlarıyla birlikte kullanıldı. Bağımlı nicel değişkenlerin, iki tekrarlı ölçümlerinin birbiri ile karşılaştırılması için Wilcoxon Signed Ranks Testi Monte Carlo simülasyon sonuçları kullanılarak test edilirken, değişkenlerinin tekrarlı nicel ölçümlerinin gruplara göre etkileşimini incelemek için General Linear Model-Repeated Anova kullanıldı. Nicel değişkenler tablolarda ortalama (standart sapma) ve Medyan (Minimum / Maximum) şeklinde ifade edilirken kategorik değişkenler ise $n(\%)$ olarak gösterildi. Değişkenler \%95 güven düzeyinde incelenmiş olup p değeri 0,05 ten küçük anlamlı kabul edildi. 


\section{Bulgular}

Çalışmaya 33 hasta (19 Crohn ve 14 ÜK) dahil edildi. Bu hastaların 12 kadın $(\% 36,4)$ ve 21 erkek $(\% 63,6)$ olduğu ve yaş ortalamalarının 28 (18-53) olduğu saptandı. Hastaların yaş, cinsiyet, sigara kullanımı, eğitim durumu ve medeni durumunun Crohn ve ÜK tanılarına göre dağılımları tablo 1 'de verilmiştir.

Tablo 1. Demografik verilerin gruplara göre dağııımı

\begin{tabular}{|c|c|c|c|c|}
\hline & $\begin{array}{c}\text { Total } \\
(\mathrm{n}=33) \\
\end{array}$ & $\begin{array}{l}\text { Crohn } \\
(n=19) \\
\end{array}$ & $\begin{array}{c}\text { Ülseratif Kolit } \\
(n=14) \\
\end{array}$ & $\mathrm{P}$ \\
\hline & $\begin{array}{c}\text { Medyan } \\
\text { (Min/Max) }\end{array}$ & $\begin{array}{c}\text { Medyan } \\
\text { (Min/Max) }\end{array}$ & $\begin{array}{c}\text { Medyan } \\
\text { (Min/Max) }\end{array}$ & \\
\hline Yaş (yıl) & $\begin{array}{c}28(18 / 53) \\
n(\%)\end{array}$ & $\begin{array}{c}28(18 / 53) \\
n(\%)\end{array}$ & $\begin{array}{c}29(19 / 42) \\
n(\%)\end{array}$ & $0.795^{u}$ \\
\hline \multicolumn{5}{|l|}{ Cinsiyet } \\
\hline Kadın & $12(36.4)$ & $4(21.1)$ & $8(57.1)$ & $0.066^{p c}$ \\
\hline Erkek & $21(63.6)$ & 15 (78.9) & $6(42.9)$ & \\
\hline \multicolumn{5}{|l|}{ Sigara } \\
\hline Yok & $21(63.6)$ & $10(52.6)$ & $11(78.6)$ & $0.160^{p c}$ \\
\hline Var & $12(36.4)$ & $9(47.4)$ & $3(21.4)$ & \\
\hline \multicolumn{5}{|l|}{ Eğitim } \\
\hline İlöğretim & $3(9.1)$ & $2(10.5)$ & $1(7.1)$ & $0.772 \mathrm{ff}$ \\
\hline Lise & $16(48.5)$ & $8(42.1)$ & $8(57.1)$ & \\
\hline Üniversite & $14(42.4)$ & $9(47.4)$ & $5(35.7)$ & \\
\hline \multicolumn{5}{|l|}{ Medeni durum } \\
\hline Bekar & $10(30.3)$ & $6(31.6)$ & $4(28.6)$ & $0.999^{f}$ \\
\hline Evli & $23(69.7)$ & $13(68.4)$ & $10(71.4)$ & \\
\hline
\end{tabular}

Hastaların tedavi öncesi ve tedavi sonrası 6. aydaki kan tetkiklerine göre sedimantasyon, CRP, Hb, Htc, Plt, Transferrin satürasyonu ve demir değerleri tablo 2 'de gösterilmiştir. Sedimantasyon, CRP ve Plt değerlerinde tedavi sonrasında istatistiksel anlamlı düşüş ve $\mathrm{Hb}, \mathrm{Htc}$, demir değerlerinde ise istatistiksel olarak anlamlı bir artış saptanmıştır. Transferrin satürasyonunda yükselme gözlenmiş ancak bu istatistiksel olarak anlamlı fark oluşturmamıştır. Hastalar Crohn ve ÜK olarak gruplandığında $\mathrm{Hb}$ ve $\mathrm{Htc}$ değerlerindeki artışın ÜK grubunda daha fazla olduğu ve bu farkın istatistiksel olarak anlamlı olduğu saptanmıştır. Tedavi öncesi ve sonrası ÜK hastalarında pMayo skorları, Crohn hastalarında da HBI skorları karşılaştırıldığında her iki grupta da istatistiksel anlamlı düşüş olduğu görülmüştür (Tablo 3).

Tablo 3. Parsiyel Mayo skoru ve Harvey-Bradsaw indekslerinin tedavi öncesi ve sonrası dağılımı

\begin{tabular}{|c|c|c|c|}
\hline & TÖ & TS & $p$ \\
\hline \multirow{3}{*}{$\begin{array}{l}\text { Parsiyel Mayo skoru } \\
\text { indeksi }\end{array}$} & Ortalama (SS) & Ortalama (SS) & \\
\hline & $12.71(2.13)$ & $5.43(0.85)$ & $<0.0011^{p t}$ \\
\hline & $\begin{array}{l}\text { Medyan } \\
\text { (Min/Max) }\end{array}$ & $\begin{array}{l}\text { Medyan } \\
\text { (Min/Max) }\end{array}$ & \\
\hline $\begin{array}{l}\text { Harvey-Bradsaw in- } \\
\text { deksi }\end{array}$ & $28(36 / 24)$ & $10(20 / 7)$ & $<0.001 w$ \\
\hline
\end{tabular}

${ }^{p}$ Pairet $t$ Test (Bootstrap), w Wilcoxon Signed Ranks Test (Monte Carlo), " Mann Whitney u test (Monte Carlo), SS.:Standart sapma, TÖ: Tedavi Öncesi, TS: Tedavi Sonrası

Tablo 2. Laboratuvar parametrelerinin gruplara göre dağııımı

\begin{tabular}{|c|c|c|c|}
\hline & $\begin{array}{l}\text { Crohn } \\
(n=19)\end{array}$ & $\begin{array}{c}\text { Ülseratif Kolit } \\
(n=14)\end{array}$ & $\begin{array}{c}\text { P değeri } \\
\text { (gruplar arası) }\end{array}$ \\
\hline & Medyan (Min/Max) & Medyan (Min/Max) & \\
\hline \multicolumn{4}{|l|}{ CRP (mg/dl) } \\
\hline TÖ & $64(38 / 180)$ & $78(31 / 164)$ & $0.592^{u}$ \\
\hline TS & $16(2 / 31)$ & $21(3 / 40)$ & $0.064^{u}$ \\
\hline Değişim (TS-TÖ) & $-55(-168 /-20)$ & $-49.5(-154 /-11)$ & 0.789 u \\
\hline P değeri (grup içi) & $<0.001 w$ & $<0.001 w$ & \\
\hline \multicolumn{4}{|l|}{ Hemoglobin (g/dl) } \\
\hline TÖ & $11(9 / 14)$ & $11(9 / 12)$ & $0.566^{u}$ \\
\hline TS & $12(9 / 14)$ & $12.5(11 / 15)$ & 0.469 u \\
\hline Değişim (TS-TÖ) & $1(-1 / 2)$ & $2(0 / 4)$ & $0.040^{u}$ \\
\hline P değeri (grup içi) & 0.006 w & $<0.001$ w & \\
\hline \multicolumn{4}{|l|}{ Transferrin satürasyonu (\%) } \\
\hline TÖ & $5.8(3.4 / 25)$ & 6.25 (4 / 14.8) & $0.878^{u}$ \\
\hline TS & $6.6(3.6 / 23.9)$ & $6.5(4.8 / 20)$ & 0.939 u \\
\hline \multirow[t]{3}{*}{ Değişim (TS-TÖ) } & $0.2(-3.9 / 7.6)$ & $0.4(-3.4 / 11.9)$ & $0.731^{u}$ \\
\hline & $0.347^{w}$ & 0.150 w & \\
\hline & Ortalama (SS) & Ortalama (SS) & \\
\hline \multicolumn{4}{|l|}{ Sedimantasyon $(\mathrm{mm} / \mathrm{h})$} \\
\hline TÖ & $42.68(22.37)$ & $49.50(18.63)$ & $0.361^{\mathrm{t}}$ \\
\hline TS & $23.74(11.89)$ & $28.36(14.44)$ & $0.321^{t}$ \\
\hline Değişim (TS-TÖ) & $-18.95(17.50)$ & $-21.14(17.65)$ & $0.725^{\mathrm{ra}}$ \\
\hline P değeri (grup içi) & $<0.001^{\mathrm{ra}}$ & $0.001^{\mathrm{ra}}$ & \\
\hline \multicolumn{4}{|l|}{$\operatorname{Demir}(\mu \mathrm{g} / \mathrm{dl})$} \\
\hline TÖ & $29.37(10.00)$ & $28.07(4.92)$ & $0.659^{t}$ \\
\hline TS & $36.37(7.23)$ & $35.07(5.92)$ & $0.587^{t}$ \\
\hline Değişim (TS-TÖ) & $7.00(6.34)$ & $7.00(3.53)$ & 0.999 ra \\
\hline P değeri (grup içi) & $<0.001 \mathrm{ra}$ & $<0.001 \mathrm{ra}$ & \\
\hline \multicolumn{4}{|l|}{ Platelet $\left(10^{3} / \mathrm{mm}^{3)}\right.$} \\
\hline TÖ & $428.26(102.32)$ & $451.93(113.82)$ & $0.536^{t}$ \\
\hline TS & $364.53(79.16)$ & 401.36 (96.89) & $0.239^{t}$ \\
\hline Değişim (TS-TÖ) & $-63.74(67.56)$ & $-50.57(52.11)$ & $0.548^{\mathrm{ra}}$ \\
\hline P değeri (grup içi) & $0.001^{\mathrm{ra}}$ & $0.003^{\mathrm{ra}}$ & \\
\hline \multicolumn{4}{|l|}{ Hemotokrit (\%) } \\
\hline TÖ & $32.84(4.02)$ & $31.93(2.09)$ & $0.444^{t}$ \\
\hline TS & $36.16(4.02)$ & $37.64(2.59)$ & $0.236^{t}$ \\
\hline Değişim (TS-TÖ) & $3.32(2.77)$ & $5.71(2.27)$ & $0.013^{\mathrm{ra}}$ \\
\hline$P$ değeri (grup içi) & $<0.001 \mathrm{ra}$ & $<0.001 \mathrm{ra}$ & \\
\hline
\end{tabular}

ra General Linear Model Repeated Anova (Wilks' Lambda), w Wilcoxon Signed Ranks Test (Monte Carlo), ' Independent samples t test, SS.:Standart sapma, TÖ: Tedavi Öncesi, TS: Tedavi Sonrası 


\section{Tartışma}

TNF- $\alpha$ inhibitörlerinin kronik enflamatuar hastalıkların tedavisinde güvenli ve etkili olduğu kanıtlanmıştır. İmmunomodülatör ve steroid tedavisine yanıtsız orta-ağır aktiviteli ÜK ve Crohn hastalığının tedavisinde anti-TNF ajanlar anahtar rol oynamaktadır.

IBH'da intestinal kayıp, mukozal inflamasyona bağlı emilimin azalması, interlökin (IL)-1, IL-6, TNF- $\alpha$ gibi inflamatuar sitokinlere bağlı ferroportin yıkımında artış ve bunun sonucu olarak hepsidinin aşırı ekspresyonu gibi nedenlerle anemi görülmektedir. TNF- $\alpha$, eritroid progenitörlerinin inhibisyonu ve demir metabolizması üzerindeki etkiler yoluyla anemiye neden olabilmesinin yanında makrofajlar içinde demir tutulması ve barsakta demir emiliminin inhibisyonuna da neden olmaktadır $(9,10)$.

Anemi, IBH hastalarında yorgunluk, huzursuz bacak sendromu, bozulmuş fiziksel ve bilişsel fonksiyonlar ve azalmış yaşam kalitesi ile ilişkilendirilmiştir (11). IBH hastalarında aneminin düzeltilmesi ile hastalık aktivitesinden bağımsız olarak hastaların yaşam kalitesinin iyileştiği gösterilmiştir (12-14). Aynı zamanda aneminin prevelansının ve ciddiyetinin IBH aktivitesiyle ilişkili olduğu ve mukozal inflamasyonu hafifletmek için kullanılan anti-TNF ajanların anemiyi iyileştirebileceği de gösterilmiştir $(5,6,15)$.

Hem ÜK hem de Crohn hastalığında oluşan anemi, $\mathrm{Hb}$, Htc, azalmış transferrin saturasyonu, artmış sedimantasyon hızı ve CRP ile ilişkilendirilmiştir (5). Bu nedenle çalışmamızda Adalimumab'ın anemi ve inflamasyon üzerine olan etkisi bu parametreler ile değerlendirilmiştir. Koutroubakis ve ark.'nın 2015 yılında anti TNF- $\alpha$ ile tedavi edilen 430 IBH hastasıyla yaptıkları çalışmada median $\mathrm{Hb}$ seviyeleri karşılaştırılmış ve özellikle 1. yıldan sonra anlamlı artış olduğu gösterilmiştir (16). Corrado ve ark.'nın çalışmasında da romatoid artrit ve psöriatik artrit hastalarında uygulanan Adalimumab tedavisi sonrasında $\mathrm{Hb}$ seviyesinin yükseldiği gösterilmiştir (17). Rubin ve ark.'nın 2011 yılında yaptıkları randomize kontrollü çalışmada 778 hasta değerlendirilmiş ve Crohn hastalarında Adalimumab tedavisinin hem 26. hem de 56. haftalarında $\mathrm{Hb}$ ve $\mathrm{Htc}$ değerlerinde yükselme gösterilmiştir (15). Romatoid artritte uygulanan Adalimumab tedavisinin de anemi üzerine iyileştirici etkisi olduğunu gösteren çalışmalar mevcuttur $(18,19)$. Çalışmamızda da literatürle uyumlu olarak $\mathrm{Hb}$ ve Htc değerlerinde her iki hasta grubunda da tedavi öncesine göre anlamlı yükselme gözlenmiştir. Iki grup kendi arasında karşılaştırıldığında ise bu artışın ÜK hastalarında Crohn hastalarına göre daha fazla olduğu saptanmıştır. Böyle bir karşılaştırmaya literatürde rastlanmamıştır. Bu durum azalmış demir alımı ve yaygın mukozal ülserasyonlardan kanama sonucu oluşan demir kaybının özellikle ÜK'te daha sık görülmesi ile ilişkilendirilebilir. Remisyonda ÜK hastalarının değerlendirildiği bir çalışmada pankolitli hastaların \% 100'ünde ve sol taraflı kolitli hastaların \% 20,8'inde anemi görülmüştür (20). Bu sonuç yaygın tutulumdan kaynaklanan artmış kayıp ve inflamasyon yükünün fazla olması ile ilişkilendirilebilir. Aynı zamanda anemi oranının hastalık süresine paralel olarak önemli ölçüde artmış olduğunu gösteren çalışmalar mevcuttur $(21,22)$. Romatoid artrit ve İB nedeniyle Adalimumab tedavisi alan hastalarda sedimantasyon ve CRP gibi inflamatuar parametrelerde belirgin azalma gösterilmiştir $(15,18,19)$. Çalışmamızda da literatürle uyumlu olarak her iki hasta grubunda da hem sedimantasyon hem de CRP değerlerinde anlamlı azalma olduğu görülmüştür. Aynı zamanda klinik aktivite indekslerindeki düşüşle tutarlı olarak CRP ve ferritin'de önemli bir azalma gözlemledik. Verilerimiz, hastalarda anormal demir homeostazı, inflamasyon ve hastalık aktivitesi arasında güçlü bir ilişki olduğunu göstermektedir.

ECCO kılavuzu, remisyonda olan IBH hastalarında her 6 ila 12 ayda, aktif hastalığı olanlarda ise her 3 ayda bir anemi parametrelerinin değerlendirilmesini önermektedir (11). Anti-TNF tedavisi başlanan IBH hastalarında tedaviye yanıt ve etkinliğin kontrolü yüklemeden sonraki 8-12. haftalarda yapılmaktadır ve 8-16 hafta içinde semptomatik düzelme ve biyogöstergelerde iyileşme varsa remisyon kabul edilmektedir. Bu nedenle çalışmamızda tedavinin 6. ayındaki veriler değerlendirilmiştir. Bulgularımız Adalimumab tedavisinin 6. ayında hastalarda aneminin iyileştiğini göstermektedir; öte yandan, daha uzun süreli bir tedavide mukozal iyileşmenin indüksiyonu boyunca anemi iyileşmeye devam edeceğinden hastanın yaşam kalitesi de artacaktır.

Cavallaro ve ark.'nın 2017 yılında yaptıkları çalışmada anti-TNF ile tedavi edilen 21 IBH hastasında tedavi öncesi ve tedavinin altınc haftasında değerler karşılaştırılmış; demir ve transferrinde artış ve CRP'de azalma saptanmıştır. Yazarlar anti-TNF tedavisinin özellikle kronik hastalık anemisi patogenezinde yer alan IL-6 üzerinden etkili olduğu ve demir metabolizmasını düzenleyerek anemiyi azalttı̆̆ını ileri sürmüşlerdir (23). Çalışmamızda her iki hasta grubunda da demir değerleri tedavi öncesine göre anlamlı olarak yükselmiştir. Transferrin satürasyonu ise tedavi sonrasında yükselmiş olup istatistiksel anlamlı fark saptanamamıştır. Bunun nedenini çalışmaya dahil edilen hasta sayısının kısıtlı kalması ile açıklayabiliriz. Birlikte ele alındığında, bu veriler Adalimumab tedavisinin demir metabolizmasını ve ardından İB'da anemiyi önemli ölçüde iyileştirdiğini göstermektedir. Bu etki, esas olarak sitokin ağının modülasyonu ile ilişkili görünmektedir.

Adalimumab ilişkili hemolitik anemi, trombositopenik mikroanjiyopati ve trombotik trombositopenik purpura geliştiğini gösteren çalışmalara literatürde rastlanmaktadır (15, 24-27). Bizim çalışmamızda da tedavi sonrasında her iki hasta grubunda da Plt değerlerinde istatistiksel anlamlı düşme gözlenmiştir. Fakat bu durum trombositopeni değildi ve tedavi sonrası inflamasyondaki azalmaya bağlandı. Çalışmalarda Adalimumab sonrası IBH hastalarında aktivite skorlarında iyileşme görülmüştür $(23,28)$. Bizim çalışmamızda da tedavi öncesi ve sonrası karşılaştırıldığında ÜK hastalarında pMayo skorları, Crohn hastalarında da HBI skorlarında anlamlı düşüş görülmüştür. 
Çalışmamızın bazı limitasyonları mevcuttu. Bunlar çalışmanın retrospektif olması, hasta sayısının azlığı, tüm hastaların hastalık yaşlarının bilinmemesi, çalışmaya dahil edilen hastaların tedavi öncesi ve tedavi sonrası 6. aydaki sonuçlarının değerlendirilmiş olmasıdır. Kronik hastalıklarda daha uzun süreli medikal tedaviler uygulanması nedeniyle bu süre kısa kalmaktadır. Ancak biz bu çalışmamızda tedavinin erken dönem sonuçlarını değerlendirmeyi amaçladık. Tek merkez verisi olduğu için küçük bir İH hastası grubu çalışmaya dahil edilebildi. Adalimumab tedavisinin etkinliği, tedaviye endoskopik ve histolojik yanıtla ilgili veriler olmadan yalnızca klinik skorlar kullanılarak belirlendi ve bir enflamatuar belirteç olan fekal kalprotektin tüm hastalarda mevcut olmadığı için değerlendirilemedi. Bu nedenle, tedavi ile klinik semptomlar arasındaki bazı olumlu etkilerin, devam eden mukozal inflamasyonun baskılanmasıyla paralel olmaması mümkündür. Ayrıca çoğu hastada zaten hafif bir aneminin olması tedavinin anemideki etkinliğinin fazla tahmin edilmesine yol açmış olabilir.

Sonuç olarak IBH nedeniyle Adalimumab tedavisi alan hastalarda aneminin düzeliyor olması hastaların yaşam kalitesini de iyileştirecektir. Bu da uzun ve düzenli takip gerektiren bu hastalıkta hastaların tedaviye inancını ve uyumunu arttıracaktır.

Etik onam: Çalışma Sanko Üniversitesi Tıp Fakültesi Etik Kurulunun 21.01.2021 tarih ve 2021/01 nolu etik izni ile yapılmıştır. Yazar Katkıları:

Konsept: $N Y$

Literatür Tarama: NY

Tasarım: NY

Veri toplama: $N Y$

Veri analizi ve yorumlama: $N Y$

Makale yazımı: NY

içeriğin eleştirel incelenmesi: NY

Çıkar Çatışması: Yok

Finansal Destek: Yok

\section{Kaynaklar}

1. Fakhoury M, Negrulj R, Mooranian A, Al-Salami H. Inflammatory bowel disease: clinical aspects and treatments. J Inflamm Res. 2014;7:113-20.

2. Sandborn WJ, Feagan BG, Lichtenstein GR. Medical management of mild to moderate Crohn's disease: evidencebased treatment algorithms for induction and maintenance of remission. Aliment Pharmacol Ther. 2007;26(7):987-1003.

3. Cassinotti A, Ardizzone S, Porro GB. Adalimumab for the treatment of Crohn's disease. Biologics. 2008;2(4):76377.

4. Plosker GL, Lyseng-Williamson KA. Adalimumab: in Crohn's disease. BioDrugs. 2007;21(2):125-32.

5. Bergamaschi G, Di Sabatino A, Albertini R, Ardizzone S, Biancheri $P$, Bonetti $E$, et al. Prevalence and pathogenesis of anemia in inflammatory bowel disease. Influence of anti-tumor necrosis factor-alpha treatment. Haematologica. 2010;95(2):199-205.

6. Peyrin-Biroulet L, Van Assche G, Gomez-Ulloa D, GarciaAlvarez L, Lara N, Black CM, et al. Systematic Review of
Tumor Necrosis Factor Antagonists in Extraintestinal Manifestations in Inflammatory Bowel Disease. Clin Gastroenterol Hepatol. 2017;15(1):25-36.

7. Lewis JD, Chuai S, Nessel L, Lichtenstein GR, Aberra FN, Ellenberg JH. Use of the noninvasive components of the Mayo score to assess clinical response in ulcerative colitis. Inflamm Bowel Dis. 2008;14(12):1660-6.

8. Harvey RF, Bradshaw JM. A simple index of Crohn's-disease activity. Lancet. 1980; 8;1:514.

9. Johnson D, Bayele H, Johnston K, Tennant J, Srai SK, Sharp $P$. Tumour necrosis factor alpha regulates iron transport and transporter expression in human intestinal epithelial cells. FEBS Lett. 2004; 27(1):195-201.

10. Papadaki HA, Kritikos HD, Valatas V, Boumpas DT, Eliopoulos GD. Anemia of chronic disease in rheumatoid arthritis is associated with increased apoptosis of bone marrow erythroid cells: improvement following anti-tumor necrosis factor-alpha antibody therapy. Blood. 2002; 15(2):47482.

11. Dignass AU, Gasche C, Bettenworth D, Birgegard G, Danese $S$, Gisbert JP, et al. European consensus on the diagnosis and management of iron deficiency and anaemia in inflammatory bowel diseases. J Crohns Colitis. 2015;9(3):211-22.

12. Evstatiev R, Marteau P, Iqbal T, Khalif IL, Stein J, Bokemeyer $B$, et al. FERGIcor, a randomized controlled trial on ferric carboxymaltose for iron deficiency anemia in inflammatory bowel disease. Gastroenterology. 2011;141(3):846-53.

13. Gasche C, Dejaco C, Waldhoer T, Tillinger W, Reinisch W, Fueger GF, et al. Intravenous iron and erythropoietin for anemia associated with Crohn disease. A randomized, controlled trial. Ann Intern Med. 1997;15(10):782-7.

14. Ott C, Liebold A, Takses A, Strauch UG, Obermeier F. High prevalence but insufficient treatment of iron-deficiency anemia in patients with inflammatory bowel disease: results of a population-based cohort. Gastroenterol Res Pract. 2012;(3):595970.

15. Rubin DT, Mulani $P$, Chao J, Pollack PF, Bensimon AG, Yu $A P$, et al. Effect of adalimumab on clinical laboratory parameters in patients with Crohn's disease: results from the CHARM trial. Inflamm Bowel Dis. 2012;18(5):818-25.

16. Koutroubakis IE, Ramos-Rivers $C$, Regueiro M, Koutroumpakis E, Click B, Schwartz M, et al. The Influence of Antitumor Necrosis Factor Agents on Hemoglobin Levels of Patients with Inflammatory Bowel Disease. Inflamm Bowel Dis. 2015;21(7):1587-93.

17. Corrado A, Di Bello V, d'Onofrio F, Maruotti N, Cantatore FP. Anti-TNF-alpha effects on anemia in rheumatoid and psoriatic arthritis. Int J Immunopathol Pharmacol. 2017;30(3):302-7.

18. Pereira ICP, Sousa NCF, Pereira DMS, Mendes SJF, Muniz TF, Colares VLP, et al. Treatment with either leflunomide or adalimumab reduces anaemia in patients with rheumatoid arthritis. An Acad Bras Cienc. 2018;90(2):2161-6.

19. Sakthiswary R, Syahrul Sazliyana S, Mohd Shahrir MS, Shahril NS, Hussein H. Beyond the joints in rheumatoid arthritis: Effects of adalimumab on hematologic and lipid indices. EXCLI J. 2012;11:142-9.

20. Chaubal A, Pandey V, Choksi D, Poddar P, Ingle M, Phadke $A$, et al. Anemia in patients with ulcerative colitis in remission: A study from western India. Indian J Gastroenterol. 2017;36(5):361-5. 
21. Bengi G, Keyvan H, Durmaz SB, Akpinar H. Frequency, types, and treatment of anemia in Turkish patients with inflammatory bowel disease. World J Gastroenterol. 2018; 24(36):4186-96.

22. Hoivik ML, Reinisch $W$, Cvancarova $M$, Moum B, group Is. Anaemia in inflammatory bowel disease: a population-based 10-year follow-up. Aliment Pharmacol Ther. 2014;39(1):69-76.

23. Cavallaro F, Duca L, Pisani LF, Rigolini R, Spina L, Tontini $\mathrm{GE}$, et al. Anti-TNF-Mediated Modulation of Prohepcidin Improves Iron Availability in Inflammatory Bowel Disease, in an IL-6-Mediated Fashion. Can J Gastroenterol Hepatol. 2017;2017:6843976.

24. Falsetti L, Sampaolesi M, Riccomi F, Nitti C. Adalimumab as a potential cause of drug-induced thrombocytopaenic microangiopathy. BMJ Case Rep. 2020;13(3):32139450.

25. Harada $Y$, Yamamoto $H$, Sato M, Kodaira M, Kono T. Autoimmune hemolytic anemia during adalimumab treatment for plaque psoriasis. Intern Med. 2015;54(9):11034.

26. Sanchez-Pujol MJ, Docampo-Simon A, Moscardo C, Betlloch-Mas I. Adalimumab-induced hemolytic anemia in a girl with psoriasis. Dermatol Ther. 2020;33(4):13711.

27. B Zbaras, L N Sam, M C Grimm Thrombotic thrombocytopenic purpura associated with adalimumab (Humira) treatment in Crohn disease. Intern Med J. 2013;43(2):216-7.

28. Loftus EV, Reinisch W, Panaccione R, Berg S, Alperovich G, Bereswill M, et al. Adalimumab Effectiveness Up to Six Years in Adalimumab-naive Patients with Crohn's Disease: Results of the PYRAMID Registry. Inflamm Bowel Dis. 2019;25(9):1522-31. 